Tohoku J. exp. Med., 1983, 141, Suppl., 465-469

\title{
The Prevalence of Diabetic Autonomic Neuropathy Indicated by Abnormal R-R Interval Variation
}

\author{
Kunisaburo Moridera, Nobuyoshi Yoshikawa and \\ Tetsuya Igarashi \\ Department of Internal Medicine, Kobe Central Municipal \\ Hospital, Kobe 650, Japan
}

\begin{abstract}
Moridera, K., Yoshikawa, K. and Igarashi, T. The Prevalence of Diabetic Autonomic Neuropathy Indicated by Abnomal $R-R$ Interval Vamation. Tohoku J. exp. Med., 1983, 141, Suppl., 465-469 — The variation in R-R interval in ECG has been reported to decrease in diabetics with autonomic neuropathy. To investigate the diagnostic value of heart rate monitoring and the prevalence of diabetic autonomic neuropathy, R-R interval variations (CVs) were measured, and the relationships between $\mathrm{CV}$ and $\mathrm{MCV}, \mathrm{FCV}, \mathrm{SCV}$, retinopathy, nephropathy, peripheral neuropathy, and duration of diabetes were investigated. 70 diabetics aged 19 - 74 were studied. A total of 100 consecutive R-R intervals on ECG were analyzed by computer. 16 patients $(22.8 \%)$ of 70 had one or more symptoms of autonomic neuropathy, while the prevalence of diabetic autonomic neuropathy indicated by abnormally low CV was $41.4 \%$. Diabetics with retinopathy, nephropathy or peripheral neuropathy had significantly lower CVs than diabetics without these complications $(p<0.01)$. The correlation coefficients for $\mathrm{CV}$ and duration of diabetes, and CV and SCV were -0.69 and 0.57 respectively $(p<0.01)$. $\mathrm{CV}(\%)$ of $\mathrm{R}-\mathrm{R}$ interval was a useful parameter for the determination of diabetic autonomic neuropathy and our results showed that autonomic nerve damage was more prevalent than were symptoms of autonomic neuropathy. _- diabetic autonomic neuropathy; $R-R$ interval variation; coefficient of variation; diabetic complications
\end{abstract}

Until the 1970s, tests of autonomic nerve function were usually complex and difficult to interpret. In 1973 Wheeler and Watkins showed that beat-to-beat heart rate variation during deep breathing was diminished in some diabetics and attributed this to vagal neuropathy since atropine, but not propranolol, abolished the heart rate variation in normal subjects.

Now measurement of beat-to-beat heart rate variation is generally accepted as a useful test of cardiac parasympathetic function (Clarke et al. 1979), but there is some debate as to which methods are of most use for measuring beat-to-beat heart rate variation (Bennett et al. 1979).

The aim of this study was to investigate the prevalence of diabetic autonomic neuropathy as defined by abnormal R-R interval variation and to establish

Address : 6-4 Minatojima-Nakamachi, Chuo-ku, Kobe, Japan. 
whether there was any relationship to the duration of diabetes, MCV, FCV, SCV or late diabetic complications.

\section{Patients}

We tested 70 diabetics ( 32 males, 38 females). Their ages ranged from 19 to 74 years and duration of diabetes from 1 to 26 years. Twelve subjects were on insulin and 39 subjects on oral hypoglycemic agents, the remainder were being treated by diet therapy only. Diabetic patients were divided into groups according to their complications.

1) Diabetic patients with autonomic neuropathy (16 patients) had one or more autonomic symptoms, namely postural hypotension (10 patients); diarrhea of a characteristic pattern (8 patients); esophageal and/or gastric atony ( 2 patients); bladder atony (4 patients ; and gustatory sweating (7 patients).

2) Diabetic patients were defined as having peripheral neuropathy if ankle jerks were absent in at least one leg.

3) Diabetic patients were defined as having persistent proteinurea if they were found to be suffering from nephropathy.

4) Diabetic patients with retinopathy were assessed by fundoscopy.

Thirty-six normal subjects with a conparable aged and sex distridbution were used as controls.

\section{Methods}

R-R intervals were measured from ECG finings and fed into the computer (ATAC-450) for immediate analysis. The $R-R$ interval variations (Coefficient of variation : $C V(\%)$ ) of 101 successive $\mathrm{R}-\mathrm{R}$ intervals (exchuding abnormal intervals) were measured with subjects lying down performing quiet breathing. MCV, FCV and SCV in the median nerve were then measured.

\section{RESULTS}

The normal subjects had a mean CV (\%) of $3.14 \pm 0.12$ (s.E.M.), and normal subjects aged 50-69 years had a mean $\mathrm{CV}(\%)$ of $2.58 \pm 0.16$. Therefore, ahnormal values for CV (\%) were defined as lower than 2.00 .

Some diabetics without diabetic autonomic symptoms had abnormlly low CV. Sixteen patients $(22.8 \%)$ of 70 had symptoms of diabetic autonomic neur-

TABLE 1. The prevalence of diabetic autonomic neuropathy in 70 diabetics indicated by clinical symptoms and by abnormally low $\mathrm{CV}(\%)$

\begin{tabular}{lcc}
\hline & Number & Frequency (\%) \\
\hline Diabetics with autonomic neuropathy indicated & 19 & 27.1 \\
by clinical symptoms & 10 & 14.3 \\
Diabetics with postural hypotension & 8 & 11.4 \\
Diabetics with diarrhea of characteristic pattern & 2 & 2.9 \\
Diabetics with esophageal or gastric atony & 4 & 5.7 \\
Diabetics with bladder atony & 7 & 10.0 \\
Diabetics with gustatory sweating & 29 & 41.4 \\
Diabetics with autonomic neuropathy in dicated by & & \\
abnormally low CV (\%) &
\end{tabular}


opathy and $29(41.4 \%)$ had abnormally low CV(\%) (Table 1$)$.

$\mathrm{CV}(\%)$ declined with duration of diabetes (Table 2), and the correlation coefficient between $\mathrm{CV}(\%)$ and duration of diabetes was $-0.69(P<0.01)$ (Table

TABLE 2. $C V(\%)$ of $R-R$ interval in diabetic groups distributed by duration of diabetes

\begin{tabular}{cccc}
\hline $\begin{array}{c}\text { Duration of diabetes } \\
\text { (years) }\end{array}$ & Number & $\begin{array}{c}\text { Mean age } \pm \text { s.E.M. } \\
\text { (years) }\end{array}$ & Eean CV (\%) \\
\hline $0-4$ & 27 & $52.9 \pm 2.6$ & $3.93 \pm 0.25$ \\
$5-9$ & 15 & $54.4 \pm 2.8$ & $2.49 \pm 0.18$ \\
$10-14$ & 11 & $57.2 \pm 1.5$ & $1.88 \pm 0.57$ \\
$15-19$ & 10 & $58.8 \pm 2.5$ & $1.57 \pm 0.07$ \\
$20-$ & 7 & $59.3 \pm 2.6$ & $1.62 \pm 0.08$ \\
\hline
\end{tabular}

TABLE 3. Relationship between $C V(\%)$ of $R-R$ interval and duration of diabetes, $M C V, F C V$, and $S C V$ in medianus (Correlation coefficent $r$ given in table)

\begin{tabular}{ccccc}
\hline & Duration of diabetes & MCV & FCV & SCV \\
\hline CV $(\%)$ & $-0.69^{*}$ & 0.39 & 0.28 & $0.57^{*}$ \\
\hline
\end{tabular}

$* p<0.01$.

TABLE 4. Mean age, duration of diabetes and $C V(\%)$ of $R-R$ interval in groups of diabetes

\begin{tabular}{|c|c|c|c|c|}
\hline Diabetic groups & Number & $\begin{array}{l}\text { Mean age } \\
\pm \text { s.E.M. } \\
\text { (years) }\end{array}$ & $\begin{array}{c}\text { Mean duration } \\
\text { of } \pm \text { s.E.M. } \\
\text { (years) }\end{array}$ & $\begin{array}{c}\text { R-R interval } \\
\text { variation } \\
\text { Mean CV }(\%) \\
\text { 土s.E.M. }\end{array}$ \\
\hline $\begin{array}{l}\text { Without peripheral } \\
\text { neuropathy }\end{array}$ & 39 & $50.0 \pm 2.1$ & $4.5 \pm 0.6$ & $3.48 \pm 0.25$ \\
\hline $\begin{array}{l}\text { With peripheral } \\
\text { neuropathy }\end{array}$ & 31 & $57.8 \pm 1.3$ & $14.3 \pm 1.0$ & $1.87 \pm 0.10^{*}$ \\
\hline Without retinopathy & 32 & $52.7 \pm 2.4$ & $4.0 \pm 0.5$ & $3.54 \pm 0.24$ \\
\hline $\begin{array}{l}\text { With simple } \\
\text { retinopathy }\end{array}$ & 29 & $57.4 \pm 1.8$ & $12.5 \pm 1.1$ & $2.22 \pm 0.17^{*}$ \\
\hline $\begin{array}{l}\text { With proliferative } \\
\text { retinopathy }\end{array}$ & 9 & $56.9 \pm 2.1$ & $16.2 \pm 1.5$ & $1.54 \pm 0.07^{*}$ \\
\hline Without nephropathy & 45 & $53.9 \pm 1.7$ & $5.4 \pm 0.6$ & $3.32 \pm 0.20$ \\
\hline $\begin{array}{l}\text { With mild } \\
\text { nephropathy }\end{array}$ & 19 & $58.0 \pm 2.3$ & $14.2 \pm 1.2$ & $1.74 \pm 0.08^{*}$ \\
\hline $\begin{array}{l}\text { With severe } \\
\text { nephropathy }\end{array}$ & 6 & $55.5 \pm 1.8$ & $18.8 \pm 1.8$ & $1.65 \pm 0.09^{*}$ \\
\hline
\end{tabular}

CV $(\%)$ of R-R interval is significantly lower in the groups with complications compared to the groups without complications $(p<0.01)$. 
3).

Table 3 shows the correlation coefficients between CV (\%) and MCV, FCV, and SCV in the median nerve. SCV correlated with $\mathrm{CV}(\%)$, and there was a slight correlation between $\mathrm{CV}(\%)$ and both MCV and FCV.

The number, age, duration of diabetes and CV $(\%)$ of diabetics with one diabetic complication (retinopathy, nephropathy or peripheral neuropathy) and without complications are shown in Table 4. Diabetics with one of these diabetic complications had significantly lower $\mathrm{CV}(\%)$ than those with no complications $(p<0.01)$.

\section{DisnCUSSION}

Since 1973, when Wheeler and Watkins (1973) showed that diabetics with autonomic neuropathy had a marked reduction in beat to beat variation, heart rate monitoring has been assessed as a useful mehod for the diagnosis of diabetic autonomic neuropathy. Now the measurement of heart rate variation is generlly accepted as a valid test of parasympathetic function.

Some parameters (Ewing et al. 1981) exist to express the degree of R-R interval variation. Kageyama et al. (1979) showed that the coefficient of variation (CV) of R-R interval in ECG in the resting supine position is a good useful parameter for diabetic autonomic function. Our findings are similar to theirs. But some studies (Mackay et al. 1980) have shown the most sensitive measurement to be that taken during deep breathing. However, the authors believe that measurement of $\mathrm{CV}$ in the resting supine position provides a simple and sensitive index of diabetic autonomic dysfunction. The prevalence of diabetic autonomic neuropathy is not yet clearly understood. Our results indicared that autonomic nerve damage, as evidenced by $R-R$ interval variation, occurs more widely than symptoms of autonomic neuropathy and the development of symptoms appears to be relatively, late. Recent reports (Ewing et al. 1976) suggest an increased mortality rate in patients with autonomic neuropathy. So when $R-R$ interval variation is abnormally low and associated with symptoms of autonomic neuropathy, the prognosis is bad (Ewing et al. 1980). Diabetics with retinopathy, nephropathy or peripheral neuropathy had significantly lower CV than diabetics who did not suffer from these complicatiots. The severty of retinopathy and nephropathy were significantly correlated with CV. These findings strongly suggest a close link between $\mathrm{CV}$ of $\mathrm{R}-\mathrm{R}$ interval and the intensity of metabolic abnormality in diabetes mellitus.

\section{References}

1) Bennett, T., Farquhar, I.K., Hosking, D.J. \& Hampton, J.R. (1978) Assessment of methods for estimating autonomic nervous control of the heart in patients with diabetes mellitus. Diabetes, 27, 1167-1174.

2) Clarke, B.F., Ewing, D.J. \& Campbell, I.W. (1979) Diabetic autonomic neuropathy. 
Diabetologia, 17, 195-212.

3) Ewing, D.J., Campbell, I.W. \& Clarke, B.F. (1976) Mortality in diabetic autonomic neuropathy. Lancet, 1, (1976) 601-603.

4) Ewing, D.J., Campbell, I.W. \& Clarke, B.F. (1980) Assessment of cardiovascular effects in diabetic autonomic neuropathy and prognostic implications. Ann. intern. Med., 92, 308-311.

5) Ewing, D.J., Brosey, D.Q., Bellavere, F. \& Clarke, B.F. (19781) Cardiac autonomic neuropathy in diabetes: Comparison of measures of $R-R$ interval variation. Diabetologia, 21, 18-24.

6) Kageyama, S., Shimizu, M., Sasoh, F., Saito, N., Tanese, T. \& Abe, M. (1979) Quantitative analysis of diabetic autonomic neuropathy. J.Jap. diab. Soc., 22, 617-634.

7) Mackay, J.D., Page, M. McB., Cambridge, J. \& Watkins, P.J. (1980) Diabetic autonomic neuropathy: The diagnostic value of heart rate monitoring. Diabetologia, 18, 471-478.

8) Wheeler, T. \& Watkins, P.J. (1973) Cardiac denervation in diabetes. Brit. med.J., $4,584-586$. 